\title{
Stereoselective Synthesis of syn-Homoallylic Alcohols
}

\section{Key words}

silaboration

rhodium

syn-homoallylic alcohols
$R^{1}, R^{2}=$ Alk, various substituted $\mathrm{Ar}$

\section{Selected examples:}<smiles>C=C(C(c1ccccc1)c1ccccc1)[C@H](O)c1ccc(Cl)cc1</smiles>

$96 \%$ yield syn/anti > 98:2<smiles>C=C(CC)C(CC)C(O)c1ccccc1</smiles>

$99 \%$ yield syn/anti > 98:2<smiles>C=C(C(C)C)C(C(C)C)[C@@H](O)c1ccc(Cl)cc1</smiles>

$95 \%$ yield syn/anti > 98:2<smiles>C=C(CC)C(CC)C(O)C1CCCCC1</smiles>

$80 \%$ yield syn/anti > 98:2<smiles>[R17]C(O)C(=C)C([R1])O</smiles>

up to $99 \%$ yield syn/anti up to $>95: 5$
Significance: The authors established a new synthetic method for the synthesis of syn-homoallylic alcohols from terminal alkynes and aldehydes. As this transformation utilizes easily accessible starting materials, this practical method should find many applications.
Comment: A cationic rhodium(I) catalyst turns 2silyl-1-alkenylboronates, which can be easily prepared from a terminal alkyne, into the corresponding allylboronate, that directly undergoes nucleophilic addition to an aldehyde to afford the corresponding syn-homoallylic alcohol in excellent stereoselectivity. 